\title{
XVI.
}

\section{Erster Bericht taber die Abtheilung für Ohrenkrankheiten der allgemeinen Poliklinik in Turin (1889-1890).}

\author{
Von \\ D1. G. Gradenigo, \\ Professor der Ohrenheilkunde an der kgl. Universităt Turin.
}

(Von der Redaction übernommen am 27. September 1890.)

Die Abtheilung für Obrenkrankheiten an der allgemeinen Poliklinik in Turin, die ich zu leiten die Ehre habe, begann ibre Wirksamkeit am 1. Juni 1889. Die Consultationen wurden anfangs blos 3 mal wöchentlich, jedesmal $1 \frac{11}{2}$ Stunden, abgehalten, später jedoch, als der Zufluss der Patienten sich steigerte, wurde es nothwendig, dieselben täglich, und zwar 2 Stunden lang zu geben; dies erfolgte vom 1. November 1890 an, mit Ausnahme der Sonntage.

In meiner Eigenschaft als Professor der Ohrenheilkunde an der kgl. Universität hielt ich während des Schuljahres 1889/90 im Hörsaal der allgemeinen medicinischen Klinik einen Curs von Vorlesungen, für welche meine Abtheilung an der Poliklinik reichliches klinisches Material bot. Um die Hörer aus dem letzten Jahrgang der Medicin in der objectiven Priffung und den wichtigsten therapeutischen Handhabungen tiben za lassen, hielt ich Abends in den Localitäten der Poliklinik, die mir vom hochverebrten Präsidium gütigst überlassen wurden, eine Reihe wöchentlicher Ohrenspiegelcurse, ftir je eine Gruppe von 8 Studenten.

Während des Schuljahres 1889/90 warde ich im Dienste von den Herren Studenten Modiano, Cordoso und Levi unterstuitzt, denen ich hier für ihre intelligente Mitwirkung meinen besten Dank sage.

Die Zahl der untersuchten und behandelten Kranken vom 1. Juni 1889 bis 30. Mai 1890 betrug 611, und zwar nach Alter und Geschlecht: 


\begin{tabular}{c|c|c|c}
\hline Alter & Münner & Weiber & Zusammen \\
\hline \hline Bis zu 11 Mon. & 1 & 2 & 3 \\
$1-15$ Jahre & 73 & 76 & 149 \\
$16-20=$ & 31 & 32 & 63 \\
$21-30=$ & 73 & 41 & 114 \\
$31-40=$ & 56 & 26 & 82 \\
$41-50=$ & 59 & 43 & 102 \\
$51-60=$ & 42 & 14 & 56 \\
$61-70=$ & 27 & 8 & 35 \\
$71-80=$ & 3 & 4 & 7 \\
\hline
\end{tabular}

Männer 59,7 Proc., Weiber 40 Proc. der Gesammtzahl der Erkrankten.

Die Consultationen waren 6375 , und zwar war die höchste Zahl $=865$ im Monat Mai 1890.

Ich halte es nicht für zweckmässig, über die Zahlen der ausgeftuhrten chirurgischen Operationen detaillirt zu berichten; es waren diese sehr zahlreich auch deshalb, weil wir bei der Behandlung der Krankheiten des Mittelobres im gegebenen Falle auch auf die chirurgische Behandlung der Krankheiten der Nasenhöhle Rücksicht nahmen. Es wurden unter anderen Operationen gemacht: Polypenextractionen aus dem äusseren Gehörgang mittelst der kalten Sehlinge, galvanokaustische Zerstörung von Granulationen in der Trommelhöhle, Incisionen von Furunkeln im äusseren Gehörgang, und die Paracentese des Trommelfells wurde bei acuter und zuweilen auch bei chronischer katarrhalischer Mittelohrentztindung (s. weiter unten iber katarrhalische Mittelohrentztindung ohne Retraction) gemacht; in letzteren Fällen verhinderte die streng antiseptisch ausgefuhrte Behandlung des Operationsfeldes das Auftreten einer eitrigen Ohrentzindung. In 2 Fällen wurden Synechien am Trommelfell zerstört. In der Nasenrachenhöhle wurden ausser der Entfernung von Polypen und bypertrophischen Schleimhautpartien der Muscheln mittelst kalter oder galvanokaustischer Schlinge Granulationen an den Rachenwänden, Verdickungen und Deviationen des Septums behandelt, theils auf blutigem Wege, theils durch die Elektrolyse nach der Methode von Garel. Ich muss jedoch erwähnen, dass Platinnadeln benutzt wurden, bei welchen die Verbindung der Nadel mit dem Rheophor eine constante war; obwohl Ströme von 15 M.-A. und oft noch intensivere zur Verwendung kamen und Sitzungen von 15 Minuten Dauer mehrere Male wiederbolt wurden, entsprachen doch die Resultate nicht unseren Erwartungen. Fur wichtigere Operationen und objective und funetionelle Unter- 
Erster Bericht der allgemeinen Poliklinik für Ohrenheilkunde in Turin, 275

suchungen waren besondere Stunden ausserhalb der Ordinationszeit bestimmt.

Die 611 Kranken zeigten $670 \mathrm{Krankheitsformen,} \mathrm{welche} \mathrm{nach}$ ibrem Sitze in folgender Weise klassificirt wurden:

Aeusseres Ohr.

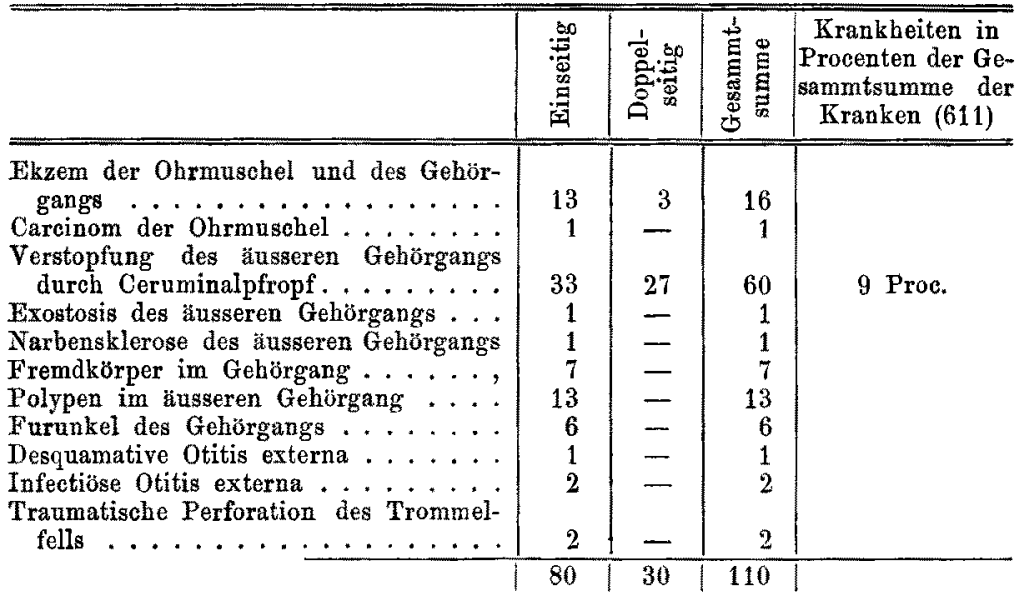

Summe der Krankheiten des äusseren Ohres $110=17$ Proc. der 611 Kranken und 16 Proc. der 670 Krankheitsformen.

Mittelohr.

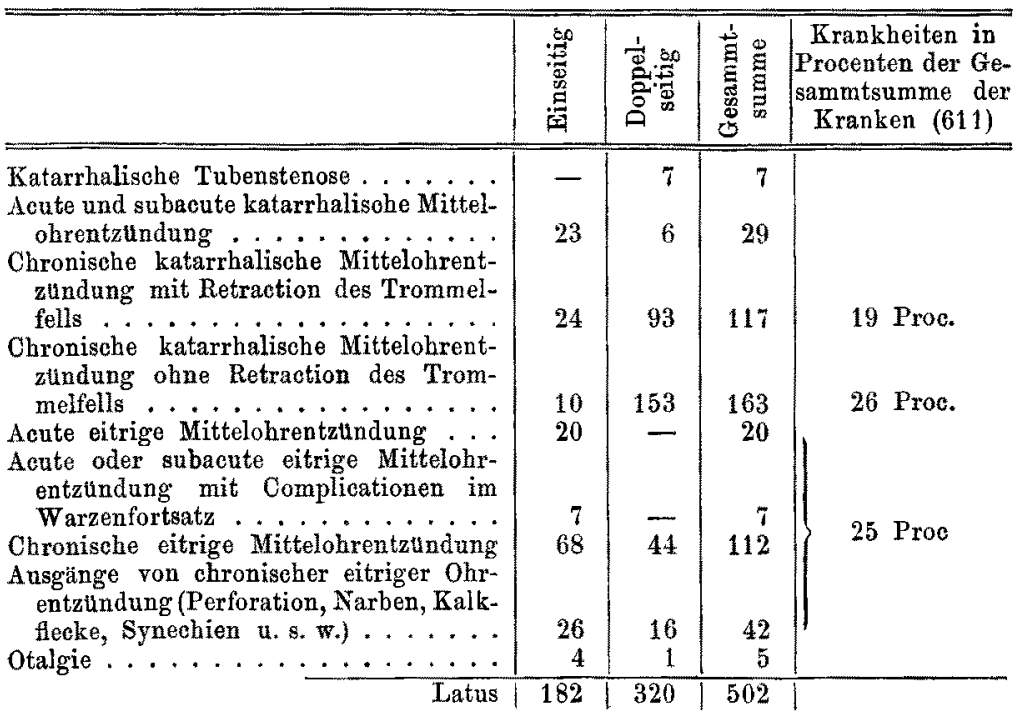




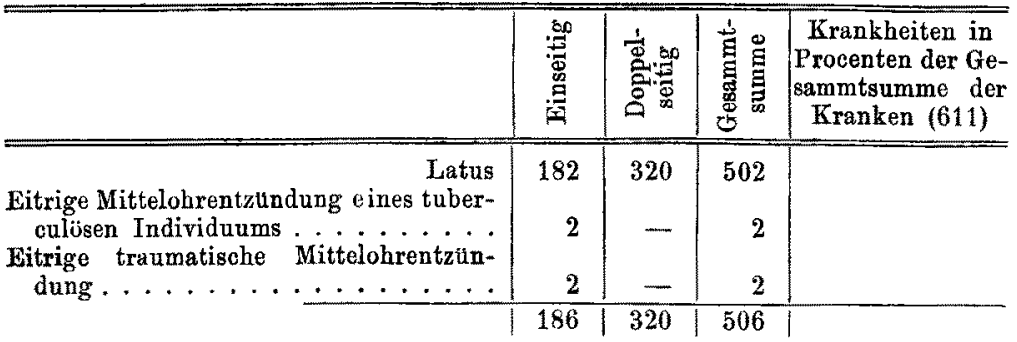

Summe der Mittelohrerkrankungen $506=81$ Proc. der 611 Kranken und 75 Proc. der 670 Krankheitsformen.

Inneres Ohr.

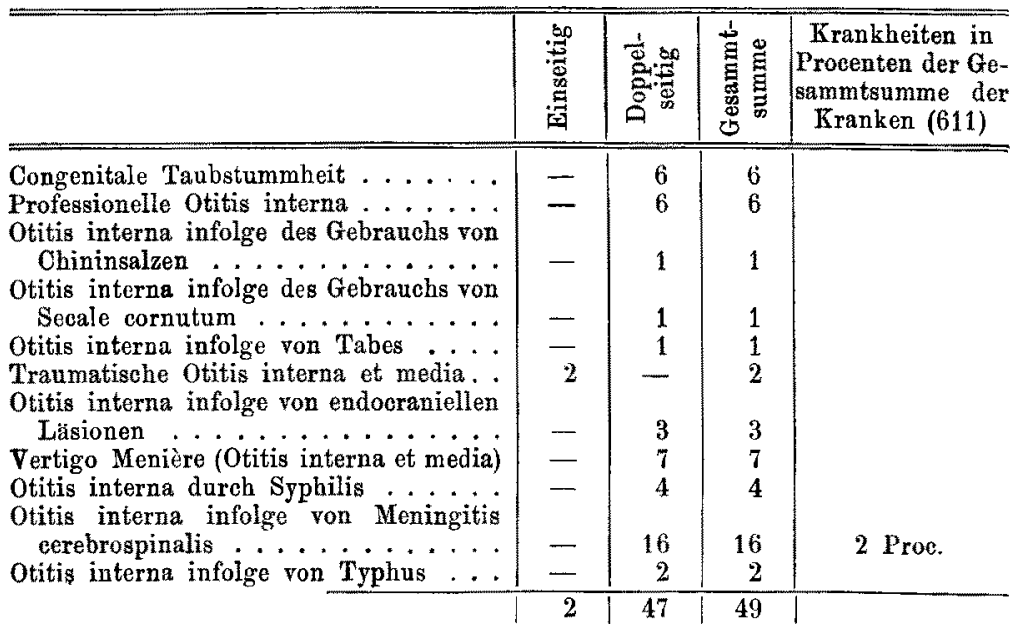

Summe der Erkrankungen des inneren Ohres $49=8$ Proc. der 611 Kranken und 7 Proc. der 670 Krankheitsformen.

Gar keine Diagnose . . . . . . . . . 1

Anderen Abtheilungen zugewiesen. . . . . 3

Muthmaasslicher Fremdkörper im Gehörgang $\frac{1}{5}$

\section{A. Aeusseres Ohr.}

Fremdkörper im Gehörgang.

Bei einer 63 Jahre alten Frau (links) und einem 4 Jahre alten Kinde (rechts) war im äusseren Gehörgang, und zwar in der Tiefe desselben ein Baumwollpfropf, der aus Vergessenheit darin belassen worden war. In 2 Fällen handelte es sich um ein 
Zündhölzchenstïck, das beim Putzen des äusseren Gehörgangs abbrach; dasselbe war in beiden Fällen in der Nähe des Trommelfells, ohne jedoch Reaction oder Schmerzen zu verursachen. Einer von diesen Patienten klagte ïber mässige subjective Geräusche, und man konnte mittelst des Obrspiegels am vorderen oberen Segment des Trommelfells eine kleine Röthung wahrnehmen. In 2 Fällen fand ich im Gehörgang je eine todte Fliege; in 1 Fall eine dicke Zwiebelschale, die vom Patienten absichtlich in den Gehörgang gesteckt worden und aus Vergessenheit 1 Monat lang darin verblieben war, ohne irgend eine Reaction verursacht zu haben.

In allen diesen Fällen bot die Extraction gar keine Schwierigkeiten.

\section{Ansammlung von Obrenschmalz.}

Es verdient der Fall eines 31 Jahre alten Schusters von zartem Körperban speciell erwähnt zu werden, der beiderseits Ansammlung: von trockenem Ohrenschmalz hatte und die Angabe machte, dass die einfache Berührung seiner Obren mit Wasser ihm schwere nervöse Erscheinungen verursache. Und in der That, kaum dass wir, durch diese Erklärung aufmerksam gemacht, die Injection lauwarmen Wassers mit grosser Vorsicht auf einer Seite begannen, wurde Patient von einer schweren Ohnmacht befallen. Man musste zur instrumentellen Entfernung der Pfröpfe schreiten, die ohne Schwierigkeiten gelang.

\section{Otitis externa a us infectiöser Ursache.}

Wenige Tage nach der Beobachtung eines Falles von acuter infectiöser äusserer Ohrentzündung in der Privatpraxis hatte ich Gelegenheit, auch in der Poliklinik eine ganz analoge Form zu beobachten. Es handelte sich hier um eine 33 Jahre alte Frau. Die Obrmuschel links war in toto geröthet, geschwollen, fast im rechten Winkel gegen die Schädelwand gestellt und bei Berïhrung sehr schmerzhaft. Die ganze vordere Ohrgegend war wie bei einem Rothlauf geröthet. Fieber fehlte, äusserer Gehörgang and Mittelohr boten nichts Abnormes. Kalte Einwickelungen und lauwarme Sublimatumschläge brachten in wenigen Tagen vollständige Heilung herbei. Die Erkrankung war evidenterweise infectiöser Natur; es konnten jedoch keine Hautläsionen nachgewiesen werden, welche eine Erklärung für den Ursprung der Infection hätten bieten können. 
Traumatische Perforation des Trommelfells.

Der nachfolgende Fall ist beweisend dafür, dass die traumatischen Läsionen des Trommelfells, wenn sie nur nicht durch empirische Curversuche inficirt werden, an und für sich zu keiner Entziindung: Veranlassung geben. Ein 40 jähriger Mann erbielt eine Ohrfeige aufs linke $\mathrm{Ohr}$, das früher immer gesund war; seit dieser Zeit hörte er bei jedesmaligem Schnäuzen Perforationsgeräusch; Schmerzen und Otorrhoe fehlten. Zur Zeit als ich ihn sab, bestand die Perforation schon seit 1 Monat; dieselbe war kreisförmig im unteren Segment der Membran in der Nähe des Umbo, es war keine Spur von Blutung oder Secretion vorhanden. Die Heilung erfolgte in wenigen Tagen nach einfacher aseptischer Tamponirung des äusseren Gehörgangs.

Ohrmuschelform.

Ich machte an den Ambulanten der otologischen Abtheilung im Laufe des Schuljahres eine Reihe von Beobachtungen über die Conformation der Ohrmusehel und verglich die normalen Fälle mit solchen von Delinquenten und Geisteskranken. Die Ergebnisse dieser Untersuchungen wurden von mir in jüngster Zeit in der medicinischen Akademie von Turin mitgetheilt '); dieselben vervollständigen frühere in dieser Richtung von mir gemachte Beobachtungen. ${ }^{2}$ )

Ich beobachtete ferner einen bemerkenswerthen Fall von angeborenem Pigmentfleck in der Hant bei einem 6 Jahre alten Kinde. Die linke Ohrmuschel zeigte einen abnorm vorspringenden Anthelix und ein stark entwickeltes Darwin'sches Knötchen. Ungefähr $1 / 2 \mathrm{Cm}$. vor der Incisura intertragea sass ein Pigmentfleck von glänzend schwarzer Farbe und ovaler Form, mit dem grössten Durehmesser $(8 \mathrm{Mm}$.) vertical gerichtet; sein kleinerer Durchmesser betrug $4 \mathrm{Mm}$. Das Hautniveau war an der Stelle des Pigmentflecks so wie in dessen Umgebung.

\section{B. Mittelohr.}

Die acuten und chronischen Erkrankungen des Mittelohres bildeten, wie man den statistischen Zablen entnehmen kann, mehr

1) Giornale della R. Accademia di medicina in Torino. Giugno 1890; vgl. auch Archiv f. Ohrenheilk. Bd. XXIX.

2) s. Giornale della R. Accademia di medicina in Torino. 1890. No.8, 9 u. 10; Verhandlungen des internationalen Congresses für Ohrenheilkunde in Paris. September 1859. 
als 80 Proc. aller Erkrankungen. Die Influenzaepidemie des vergangenen Winters verursachte eine grosse Zahl von Ohrentztindungen, welche, wie weiter unten gezeigt wird, Gegenstand von besonderen Untersuchungen bildeten. Ich habe zu den Krankheiten des Mittelohres auch jene chronisch-katarrhalischen Formen gerechnet, in denen sich der krankhafte Process auf das Labyrinth fortsetzte.

Acute Mittelohrentzündung bei Influenza.

Die hierher gehörigen Formen benutzte ich zu speciellen klinischen und bacteriologischen Untersuchungen, deren Ergebnisse zum Theil in den Annales des maladies des oreilles ${ }^{1}$ ) mitgetheilt wurden. Im bacteriologischen Theil dieser Arbeit unterstitzte mich Herr Dr. Bordoni-Uffreduzzi. Nachfolgend möchte ich einige der interessanteren Fälle kurz erwähnen.

Hämorrhagische äussere Mittelohrentzündung in folge von Influenza, gekennzeichnet durch Staphylococcus pyogenes albus.

N. N., 27 Jahre alte Hebamme, litt nie an Ohrenkrankheiten; sie hatte zwei Anfälle von Influenza. Der erste verlief ohne irgend eine Störung, vor dem zweiten Anfall jedoch, der 2 Monate nach dem ersten auftrat, hatte sie 2 Tage lang Fieber mit vorangehendem Kälteschauer, Am 3. Tage verspürte Patientin heftige Schmerzen am linken $\mathrm{Ohr}$ und am 8. Tage entstand spontan eine kleine Perforation im Trommelfell. Am darauffolgenden Tage sah ich sie zum ersten Male und fand an der unteren Wand des knöchernen äusseren Gehörgangs ein kleines schwärzliches Bläschen, aus welchem, nach Einstich, dünes blutiges Serum ausfloss, ferner eitrige Mittelohrentzuindung.

Die bacteriologische Untersuchung ergab, dass sowohl im Eiter, wie auch im Serum des genannten Bläschens Staphylococcus pyogenes aureus in Reineultur vorhanden war. Die Otitis verlief ohne Complicationen.

Acute Otitis media infolge von Influenza (Diplostreptococeus).

N. N., 72 Jahre alte Frau aus Turin. Während der Abendstunden in der Poliklinik wurde ich in aller Eile zu dieser Patientin gerufen, die seit 2 Tagen heftige Schmerzen im rechten Ohr, Kopfschmerzen und Fieber hatte. Vor 15 Tagen hatte sie die Influenza. Ich fand intensive Hyperämie am rechten Trommelfell, weder Hämorrhagie, noch hämorrhagische Bläschen, machte sofort eine breite Paracentese, desinficirte mit Sublimat.

1) Les affections de l'organe de l'onie dans l'influenza. Maggio 1890. 
Im Eiter war Diplococcus pneumoniae in Reincultur enthalten. Der Verlauf bot keine Complicationen.

Subacute eitrige Mittelobrentzündung infolge von Influenza (Staphylococens pyog. albus).

S. L., 28 Jahre alter Bauer, spïrt nach einer Erkrankung an Influenza seit ungefähr 1 Monat Schmerzen im linken Ohr. Das Trommelfell ist gleichmässig geröthet, nicht perforirt. Es wurde die Paracentese gemacht und durch das kiunstliche Loch im Trommelfell mittelst einer Platinschlinge eine kleine Menge Secret aufgesammelt. Es entwickelte sich eine Reincultur von Staphylococeus pyog. albus. Die Krankheit verlief ohne Complicationen.

Hämorrhagische Otitis externa infolgevon Influenza (Diplostreptococeus).

Clotilde R., 19 Jahre alt, fühlte während ihrer Erkrankung an Influenza heftige Schmerzen im rechten Ohr. Am 3. Tage der Krankheit erfolgte aus dem entsprechenden Gebörgang ein blutiger Ausfluss. Die Wände des letzteren waren angeschwollen und mit schwärzlichen Krusten belegt, von derselben Farbe war auch das Trommelfell.

Aus den Culturen mit dem Secret entwickelte sich Diplococcus. Die Krankheit hatte regelmässigen Verlauf.

Acute Mittelohrentzündung infolge ron Influenza. Paracentese. (Diplostreptococeus.)

Luigi L., 30 Jahre alt, hatte Schmerzen in den Ohren seit 24 Stunden. Das Trommelfell war geröthet und angesehwollen; dasselbe ebenso wie der Gehörgang zeigen keine hämorrhagischen Bläschen. Paracentese im hinteren unteren Segment des Trommelfells. Diplostreptococcus in Reincultur. Sublimatbehandlung. Verlanf der Krankheit giünstig.

Es resultirt aus den mitgetheilten Beobachtungen, dass die acute Mittelohrentzündung bei Influenza durch verschiedene pathogene Mikroorganismen bedingt sein kann, ebenso wie die sogenannte genuine Form, und dass die klinischen Symptome nicht, wie einige Autoren annahmen, in directem Verhältniss zur Gattung des Mikroorganismus stehen, der die Infection hervorbrachte.

Trennung von Adhäsionen in der Trommelhöhle mittelst der Politzer'schen Luftdouche.

V. S., 18 Jahre alt, leidet schon seit ihrer Kindheit an periodisch wiederkehrenden Schmerzen in beiden Ohren, die 5-6 Tage dauern und spontan aufhören, ohne von Otorrhoe gefolgt zu werden. Patientin klagt iber persistirende Ohrgeräusche und progressive Taub- 
heit. Rechts ist das retrahirte Trommelfell dem Promontorium adbärent, am unteren Segment eine erbsengrosse Narbe. Das linke Trommelfell ist ebenfalls adhärent. Durch eine energische $P_{0}$. litzer'sche Luftdouche wurden die Adhäsionen und die Narbe zerrissen, wobei in die Trommelhöhle und nach anssen durch den Gehörgang Blut ausfloss. Das Trommelfell nahm wieder seinen normalen Platz ein. Genaue Desinfection, Einträufelung von Glycerin-Sublimat. Aseptischer Verlauf, Besserung der Hörschärfe, Aufhören der Geräusche.

Eitrige traumatische Mittelohrentztindung.

Giovanni M., 51 Jahre alt, fiel im Rausche mit dem Kopf gegen die Erde, wobei viel Blut aus dem rechten Ohr herausfloss. Schwindelanfälle, subjective Gerảusche u. s. w, Er kam 5 Tage später auf die Poliklinik und klagte uber Schmerzen in der rechten Gesichtshälfte; die besonders bei Bewegungen des Kiefers sehr stark warden. Es waren geringfugige Ekchymosen an der linken Jochbeingegend und an der linken Seite des Nasenrickens, ferner ausgedehnte Ekchymosen an der Warzenfortsatzgegend gleich hinter der Insertion der $\mathrm{Ohr}$ muschel vorhanden.

Im vorderen unteren Segment des rechten Trommelfells bestand eine kreisförmige Perforation; das Trommelfell selbst ist schwarz gefärbt mit einem intensiver colorirten Fleck am hinteren Umfang. Es erfolgte Heilung ohne Complicationen.

Das klinische Material der otiatrischen Abtheilung wurde im Laufe des Schuljahres zu einigen wissenschaftlichen Untersuchungen ïber Mittelohrentzündungen benutzt, von welchen ich nur die wichtigsten andeuten möchte.

Katarrhalische Mittelohrentztindung ohne Retraction des Trommelfells.

Bacteriologische Beobachtungen über den Inhalt der Trommelhöhle.

Um zu entscheiden, ob bei dieser Krankheit in der Trommelhöhle pathogene Keime vorhanden sind oder nicht, wählte ich einige typische Fälle heraus, deren gewöhnliche Behandlung nur geringe Resultate erreichen liess. Es wurde auf einer Seite galvanokaustisch eine breite ringförmige Perforation des Trommelfells gemacht, nach vorausgehender Sterilisation des äusseren Gehörgangs und der Instrumente, dann wurde durch die künstliche Oeffnung eine sterilisirte Platinschlinge, die mit destillirtem Wasser befeuchtet wurde, in die Trommelhöhle eingeführt und mit der Schleimhaut der Vorhofswand in Verbindung gebracht. Ich bereitete dann nach den gewöhnlichen Methoden Flacheulturen 
auf verschiedenen Nährböden. In 4 dieser Fälle blieben die Culturen steril, in 2 entwickelte sich eine nicht pathogene Coccusart, die sehr häufig in der atmosphärischen Luft vorkommt: der Flugge'sche Micrococeus cereus albus, was ich für einen zufälligen Befund halte.

Bacteriologische Beobachtungen über den Inhalt der Eustachi'schen Trompete bei katarrhalischer Mittelohrentzundung ohne Retraction des Trommelfells.

Gleichfalls negativ waren die Untersuchungen, die ich in Gemeinschaft mit Prof. Maggiora anstellte, um zu bestimmen, ob bei erwähnter Erkrankung in der Tuba Eustachii pathogene Keime vorhanden sind oder nicht. Wir konnten in 13 Beobachtungen, die mit allen nothwendigen Vorsichtsmaassregeln und nach einer besonderen Methode ausgeführt wurden, blos die Existenz sehr weniger Fäulnissbacterien nachweisen.

Wir müssen auf Grund dieser Untersuchungen annehmen, dass die trockene katarrhalische Mittelohrentzitndung, wenigstens in der Periode der Atrophie, nicht von Mikroorganismen abhänge.

Eitrige Mittelohrentztindug.

Bei dieser Krankheitsform erhielt ich mit der antiseptischen Behandlung, speciell mit Sublimat, glänzende Resultate. In acuten Fällen pflege ich bei Zeiten eine breite Paracentese mit dem Messer oder dem Galvanokauter zu machen. Bei acuter Mastoiditis gelang mir oft die Abortivcur durch eine Combination der antiseptischen Behandlung mit der antiphlogistischen. Wirkungsvoll in solchen Fällen erwiesen sich mir Waschungen der Trommelhöhle durch die Tuba.

Ausser den bacteriologischen Studien bei acuter Ohrentzündung, die ich oben bei Besprechung der Ohrentzündungen infolge von Influenza erwähnte, habe ich in Gemeinschaft mit Dr. Penzo eine Reihe von bacteriologischen Beobachtungen über chronische eitrige Obrentzündungen gemacht. Es geht aus unseren Beobachtungen hervor, dass das Secret aus einem Obr mit chronischer eitriger Obrentztindung, die, wenn auch nur seit einigen Tagen, mit Waschungen oder Einträufelungen von $1 / 4-1$ pro mille Sublimatlösung behandelt wird, nur sehr geringe Mengen von pathogenen Mikroorganismen zeigt und, unter die Haut von weissen Mäusen injicirt, gar keine pathogene Wirkung ausibt. 
Erster Bericht der allgemeinen Poliklinik für Ohrenheilkunde in Turin. 283

\section{Inneres Ohr.}

Ausgänge von Entzïndung des Nervus acusticus und von Otitis interna infolge von Meningitis cerebrospinalis.

Sehr häufig waren die Fälle von Taubheit infolge von $\mathrm{Me}$ ningitis cerebrospinalis; gewöhnlich handelte es sich um Kinder und die Taubheit war eine totale. Bemerkenswerth war in einem Falle die Coincidenz von Taubheit infolge von Meningitis cerebrospinalis mit choreaartigen Bewegungen, namentlich des Gesichts; in einem zweiten Falle mit Kinderlähmung nach Poliomyelitis.

Die abortive Meningitis crebrospinalis mit consecutiver Läsion des Nervus acusticus und des Labyrinths bedingt zuweilen keine vollkommene Taubheit. Im folgenden Falle war es mir möglich, die Charaktere der functionellen Störungen zu studiren.

Maria C., 18 Jahre alt, hatte, als sie 1 Jahr alt war, eine fieberhafte Krankheit mit den Symptomen der Meningitis; zu derselben Zeit starb infolge einer ähnlichen Krankheit ein 7 Jahre alter Bruder von ihr; in der Reconvalescenzperiode hatte sie einen taumelnden Gang und lernte sehr schwer sprechen. Die objective Prufung lehrt, dass beide Trommelfelle mässig retrahirt und glänzend sind; Nasenhöhlen normal.

Diapason-Vertex auf der Mitte des Kopfes.

Linkes $0 \mathrm{hr}$. Uhr $\% / 200 ;$ Flistersprache $=0$; Conversationssprache in der Nahe.

Rechtes $\mathrm{Ohr}$. Uhr $0 / 200 ;$ Flistersprache $=0$; Conversationssprache $0,50 \mathrm{Cm}$.

\section{Linkes $\mathrm{Ohr}$}

Dauer der Perception per Iuftleitung

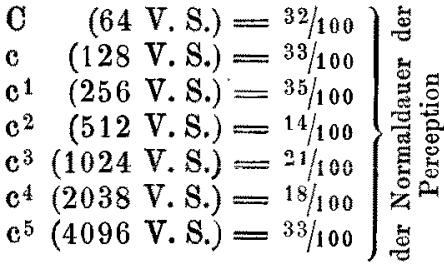

Rechtes Ohr

Dauer der Perception per Luftleitung

Sehr hohe Töne bis $\mathrm{c}^{8}$ percipirt.

Die elektrische Prüfung des Acusticus negativ.

Wir haben also eine ungleichmässige Vertheilung der functionellen Störung längs der musikalischen Tonleiter; die tiefen Töne werden im Allgemeinen besser gehört, als die bohen.

$$
\text { Professionelle Otitis interna. }
$$

Diese charakteristische Form von Taubheit und Schwindelanfällen wurde meistentheils bei Schmieden und Mechanikern 
angetroffen. Einer dieser Fälle ist wegen seiner Aetiologie besonders interessant.

Es handelte sich um einen 34 Jahre alten Mechaniker, der seit mehr als 13 Jahren in einer Werkstätte beschäftigt ist, wo beständig grosses Getöse herrscht; rechts von ihm arbeitet ein Kolben mit vielen und heftigen Schlägen in der Minute, links eine Maschine, die ein tiefes Geräusch erzeugt. Vor 3 Jahren erzeugte eine Metallplatte, die er bearbeitete, einen sehr intensiven Klang, so dass Patient von sehr starken Schwindelanfällen und persistirenden subjectiven Geräuschen befallen wurde (subjectiv rechts $\mathrm{c}^{1}=256 \mathrm{~V}$.S., links $\mathrm{c}=128$ V.S.); die functionellen Störungen sind charakteristisch, d. h. sie sind dentlicher für die hohen Töne.

Rechts kann man mittelst des galvanischen Stromes weder die subjectiven Geräusche modificiren, noch eine Reaction des N. acusticus hervorrufen, links erfolgt unter der Wirkung von An (5 M.A.) vollständiges, aber nur temporäres Aufhören der Geräusche und leichte Reaction des Acusticus.

Ich werde auch noch andere Fälle von Otitis interna, die mir bemerkenswerth erscheinen, kurz andenten.

\section{Traumatische Otitis media interna.}

Francesco B., 32 Jahre alt, machte am 2. Juni 1889 einen Selbstmordversuch, indem er zwei Revolverschüsse gegen die rechte Kopfseite und einen gegen die Brust abfeuerte. Es scheint, dass er hierbei keine schweren Verletzungen erlitt, hatte jedoch nachher Paralyse des Nerv. facialis auf der rechten Seite und Otorrhoe. Gegenwärtig ist das Trommelfell rechts opak, mit einem schwärzlichen Fleck in der Nähe des Umbo. Links (besseres Ohr) D.-V. Rechts D. Rinne positiv.

Die functionelle Prüfung mit der Stimmgabel ergiebt eine Parese des Schallempfindungsapparates, indem ein beträchtlicher Grad von Verminderung der Hörschärfe für hohe Töne vorhanden ist.

Gar keine elektrische Reaction mit 7 M.-A., EIII.

\section{Paralyse des Acusticus und Parese des Facialis infolge von Trauma.}

Giovanni C., 23 Jahre alt, fiel im betrunkenen Zustand mit dem Kopf rückwärts aufs Pflaster von einer ungefähr 2 Meter hohen Stelle. Auf ihn, und zwar aufs Gesicht, fiel ritcklings ein Anderer. Infolge des Falles war Patient 10 Stunden besinnungslos, erbrach mit Blut gemischten Wein, verlor Blut aus der Mund- und Nasenhöhle. Als er zu sich $\mathrm{kam}$, hatte er vom Vorgefallenen gar keine Kenntniss und fieberte leicht; Kopfschmerzen waren nicht vorhanden, die Extremitäten erlitten gar keine Verletzungen. Patient stiitzt sich beim Gehen auf einen Stock, sein Gang mit gespreizten Beinen und bei offenen Augen ist schwankend, fast unmöglich bei geschlossenen Augen; links besteht Taubheit und persistirende subjective Geräusche. 
Die objective Untersuchung lässt hier mässige Facialislähmung der unteren Gesichtshälfte erkennen; Zunge und Zäpfchen sind nach links abgewichen. Ophthalmoskopischer und otoskopischer Befund negativ, links fehlt jede akustische Perception. Auf den linken Warzenfortsatz applicirte tiefe Stimmgabeln werden rechts percipirt. Uhr, Fliusterstimme $=$ Null.

Auf der rechten Seite werden tiefe und mittlere Töne bis $\mathbf{c}^{3}$ vernommen, hingegen ist die Perceptionsdaner fur $\mathrm{c}^{4}=75 / 100$, fur $\mathrm{c}^{5}=25 / 100$ der normalen Perceptionsdauer. Daselbst wird Flüstersprache in der Nahe percipirt, Conversationssprache auf 5 Meter.

Die sehr hohen Töne von $\mathrm{c}^{5}$ nach oben werden gar nicht percipirt, elektrische Reaction auf beiden Seiten ganz deutlich. Es besteht demnach Paralyse des linken und Parese des rechten Acusticus, ferner Parese der unteren Aeste des linksseitigen Nervus facialis.

Tabes dorsalis infolge von Syphilis. Atrophie der Seh - und Gebörnerven.

Alberto C., 39 Jahre alt, hatte Syphilis vor 16 Jahren; vor 6 Jahren erfolgte bei ihm progressive Abnahme der Sehschärfe links, später specifische Darm- und Kehlkopferscheinungen. Seit 2 Jahren bestehen persistirende Ohrgeränsche links und Herabsetzung der Hörschärfe. Die von einem Specialisten vorgenommene Behandlung der Nasenrachenhöhle hatte gar keinen Erfolg. Seit einem Jahre ist auch das rechte Ange vollständig erblindet. Gegenwärtig zeigt der Patient eine Schwäche in den Beinen, Eingenommenheit des Kopfes, Fehlen der Patellarreflexe, links leichte Myosis und Parese des Rectus internus oculi.

Die ophthalmoskopische Untersuchung ergiebt sehr weit vorgeschrittene Sehnervenatrophie auf beiden Seiten.

Uhr wird links nicht gehört, rechts $0 / 200$ auf dem Wege der Knochenleitung, $25 / 200$ in der Luftleitung. Flïsterstimme links nicht, rechts 1 Meter.

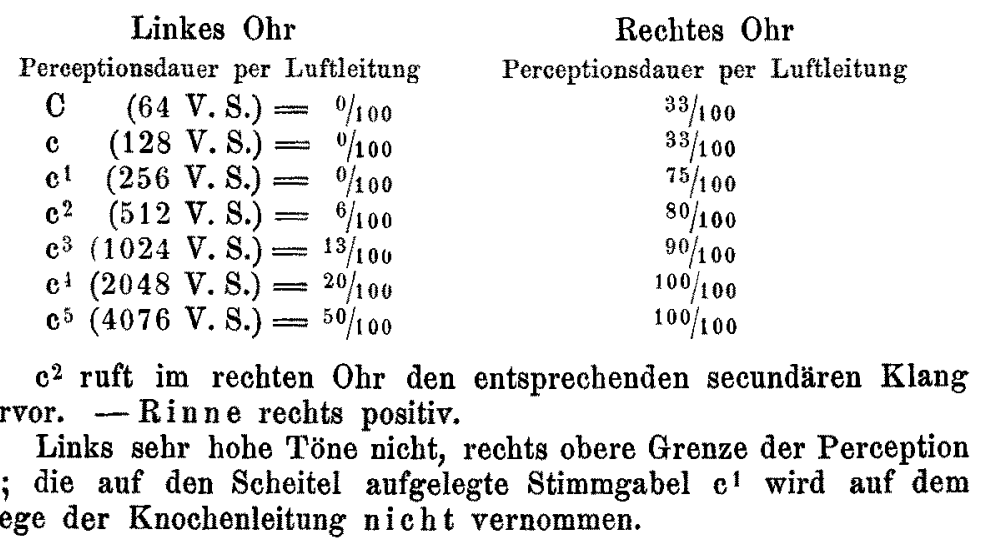


286 XVI. GRADENIGO, Erster Bericht d. Poliklinik f. Ohrenheilk. in Turin.

Eine Steigerung der elektrischen Reizbarkeit des N. acusticus kann nicht constatirt werden.

Dieser Fall ist deshalb sehr wichtig, weil er zeigt, dass bei Erkrankungen des Nervus acusticus eine Vertheilung der functionellen Störungen statthaben kann, welche ganz analog derjenigen ist, welche bei Erkrankungen des schallleitenden Apparates vorkommt. 